\title{
Characterization of polybrominated diphenyl ethers (PBDEs) and hydroxylated and methoxylated PBDEs in soils and plants from an e-waste area, China
}

\author{
Sen Wang ${ }^{\mathrm{a}, \mathrm{b}}$, Shuzhen Zhang ${ }^{\mathrm{a}, *}$, Honglin Huang ${ }^{\mathrm{a}}$, Zhenchuan Niu ${ }^{\mathrm{c}}$, Wei Han ${ }^{\mathrm{a}}$ \\ ${ }^{a}$ State Key Laboratory of Environmental Chemistry and Ecotoxicology, Research Center for Eco-Environmental Sciences, Chinese Academy of Sciences, P.O. \\ Box 2871, Beijing 100085, China \\ ${ }^{\mathrm{b}}$ Department of Environmental Sciences, College of Urban and Environmental Sciences, Northwest University, Xi'an 710027, China \\ ${ }^{\mathrm{c}}$ Key Laboratory of Urban Environment and Health, Institute of Urban Environment, Chinese Academy of Sciences, Xiamen 361021, China
}

\section{A R T I C L E I N F O}

\section{Article history:}

Received 28 May 2013

Received in revised form

5 September 2013

Accepted 13 September 2013

\section{Keywords:}

PBDEs

OH-PBDEs

MeO-PBDEs

E-waste

Soil-plant system

\begin{abstract}
A B S T R A C T
In order to characterize polybrominated diphenyl ethers (PBDEs), and hydroxylated and methoxylated PBDEs (OH-PBDEs and MeO-PBDEs) in the soil-plant system, soil and plant samples were collected from an e-waste recycling area in China. Forty one PBDEs, twelve OH-PBDEs and MeO-PBDEs were detected in the soil and plant samples. Concentrations of PBDEs in roots were significantly correlated to their concentrations in the soils, but the percentages of lower brominated congeners in the plants were higher than those in the soils. Significant positive linear relationships exist between concentrations of $\sum \mathrm{OH}-$ PBDEs and $\sum \mathrm{MeO}-\mathrm{PBDEs}$ with higher levels of $\sum \mathrm{MeO}-\mathrm{PBDEs}$ than those of $\sum \mathrm{OH}$-PBDEs in the soils, plant roots and leaves. A majority of the OH-/MeO-PBDEs had the hydroxyl or methoxy group at the ortho-positions to the biphenyl bond for most of the plant species. However the occurrence of meta- and para- substituted $\mathrm{OH}-/ \mathrm{MeO}-\mathrm{PBDEs}$ in soils and plants were also confirmed.
\end{abstract}

(c) 2013 Elsevier Ltd. All rights reserved.

\section{Introduction}

Electronical and electric waste (e-waste) includes end-of-life electronic products such as computers, printers, television sets, mobile phones, photocopy machines, etc. Due to the widely application of brominated flame retardants (BFRs) such as polybrominated diphenyl ethers (PBDEs) in these electronic products, uncontrolled dismantling, acid treatment, and open burning of ewaste result in the emission of PBDEs into the ambient environment (Leung et al., 2006; Wong et al., 2007). Therefore, the growth of e-waste recycling industry particularly in the developing countries has drawn much attention as the source of environmental contamination with PBDEs (Betts, 2009; Leung et al., 2006; Ma et al., 2009).

Soil is the main disposal and landfill receptor for e-wastes. High PBDE concentrations have been found in the soils from e-waste recycling areas such as in Guiyu, Guangdong Province (up to $4250 \mathrm{ng} \mathrm{g}^{-1}$, Leung et al., 2007) and Taizhou, Zhejiang Province (up to $25,479 \mathrm{ng} \mathrm{g}^{-1}$, Yang et al., 2008) in China. PBDEs in soils can be taken up by crops (Huang et al., 2010; Wang et al., 2011a) and

\footnotetext{
* Corresponding author.

E-mail address: szzhang@rcees.ac.cn (S. Zhang).
}

translocated through the food chain, which potentially threatens the ecological environment and human health (Sun et al., 2013a; Yu et al., 2011; Zhao et al., 2009). Although investigations have been conducted on soil contamination with PBDEs in e-waste recycling areas (Leung et al., 2007; Liang et al., 2010; Luo et al., 2009; Yang et al., 2008), studies are limited on the behaviors of PBDEs in the soil-plant system at e-waste sites.

Moreover, PBDEs in the environment have been shown to break down into lower brominated congeners by soil microbial (Betts, 2008; He et al., 2006; Robrock et al., 2008), photochemical (Eriksson et al., 2004; Shih and Wang, 2009) and plant degradation (Huang et al., 2010; Wang et al., 2011a). Lower brominated PBDEs which are not included in the commercial mixtures have been widely detected in the environmental matrices (Huang et al., 2011; Gerecke et al., 2005; La Guardia et al., 2007; Stapleton et al., 2004; Van den Steen et al., 2007). OH-PBDEs and MeO-PBDEs have been found in marine organisms (algae, mussel and fish), human blood, plants and abiotic samples such as surface water, snow, rain, soils and marine sediments (Bradley et al., 2011; Malmvärn et al., 2005; Marsh et al., 2004; Sinkkonen et al., 2004; Sun et al., 2013a; Ueno et al., 2008; Verreault et al., 2005; Zhang et al., 2012). Recent studies also detected OH-PBDEs and MeO-PBDEs in organisms and plants after in vivo PBDE exposures (Marsh et al., 2006; Qiu et al., 2007; Sun et al., 2013b; Wan et al., 2010; Wang et al., 2012). 
However, their origin is far from clear. It is generally realized that ortho-substitued OH-PBDEs and MeO-PBDEs are formed as naturally occurring compounds in marine ecosystems (Teuten et al., 2005; Wan et al., 2009), while meta- and para-substituted compounds originate from biotransformation of PBDEs (Wan et al., 2010). Debromination PBDEs or biotransformation of PBDEs to OH-PBDEs and MeO-PBDEs if exists may bring additional adverse influences to bear on the environment and human health. Nevertheless, up to date, information on the occurrence and distribution characteristics of OH-PBDEs and MeO-PBDEs in the soil-plant system is still very limited.

The aim of the present study was to investigate the occurrence and distribution characteristics of PBDEs, OH-PBDEs and MeOPBDEs in the soil-plant system. Soil and plant samples were collected from an e-waste recycling area in Guangdong Province, Southern China. The concentrations of 57 PBDEs and 12 OH-PBDEs and MeO-PBDEs in the soils and plant roots and leaves were determined. The levels and compositions of PBDEs, OH-PBDEs and MeO-PBDEs in the soil-plant system were characterized and discussed.

\section{Materials and methods}

\subsection{Chemicals}

Standards of BDE-209, PCB-30 and PCB-209 were obtained from Sigma-Aldrich (Sigma-Aldrich, Inc., St. Louis, MO, USA), and standards of ${ }^{13} \mathrm{C}-\mathrm{PCB}-141$ and ${ }^{13} \mathrm{C}-\mathrm{PCB}-208$ were purchased from Cambridge Isotope Laboratory (Andover, MA, USA). A standard solution of PBDEs containing 16 native congeners (octa- through deca-BDEs) and standard of ${ }^{13} \mathrm{C}-6-\mathrm{OH}-\mathrm{BDE} 47$ were purchased from Wellington Laboratories, Inc., Guelph, Ontario, Canada. A standard solution of PBDEs containing 39 native congeners (mono- through heptaBDEs), OH-PBDE standards (2'-OH-BDE3, 3'-OH-BDE7, 4'-OHBDE17, 3'-OH-BDE28, 3-OH-BDE47, 5-OH-BDE47, 6-OH-BDE47, 4'OH-BDE49, 2'-OH-BDE68, 6-OH-BDE85, 5'-OH-BDE99 and 6'-OHBDE99) and MeO-PBDE standards (2'-MeO-BDE3, 3'-MeO-BDE7, 4'MeO-BDE17, 3'-MeO-BDE28, 3-MeO-BDE47, 5-MeO-BDE47, 6-MeO-
BDE47, 4'-MeO-BDE49, 2'-MeO-BDE68, 6-MeO-BDE85, 5'-MeOBDE99 and 6'-MeO-BDE99) were purchased from AccuStandard (AccuStandard, New Haven, USA). Anhydrous sodium sulfate $\left(\mathrm{Na}_{2} \mathrm{SO}_{4}\right)$, silica gel and alumina (100-200 mesh) were washed with hexane and used after heating overnight at $150{ }^{\circ} \mathrm{C}$. Florisil (60-100 mesh, Acros Organics) was activated at $450{ }^{\circ} \mathrm{C}$ for $12 \mathrm{~h}$ and deactivated by adding $1 \%(\mathrm{w} / \mathrm{w})$ water. All solvents used, i.e., methyl tertbutyl ether (MTBE), dichloromethane (DCM), hexane, methanol, acetonitrile and acetone, were of HPLC grade and purchased from Fisher Scientific (Fair Lawn, NJ, USA). All the other chemicals and reagents used were of reagent grade. Ultrapure water (18.2 M $\Omega$ ) used was obtained by using a Milli-Q system (Milli-Q Advantage A10, Millipore Corporation, Billerica, MA, USA).

\subsection{Sample collection and treatment}

Qingyuan country is located in Guangdong Province, $50 \mathrm{~km}$ north of Guangzhou. More than 1300 workshops, mainly distributed within two administrative towns (Longtang and Shijiao), where e-waste dismantling and recycling activities are conducted. Uncontrolled e-waste processes such as open burning and acid washing left contaminated sites scattered among agricultural fields, and electronic scraps were dumped near ponds. Meanwhile, agriculture activities are still going on in this area. The soil and plant samples were collected in 2011 in Longtang town (between $113^{\circ} 01$. and $113^{\circ} 02$ east longitude and between $23^{\circ} 32$ and $23^{\circ} 35$ north latitude), and the four sampling sites, site 1 (a residential area of Matou village), site 2 (an e-waste dismantling area near Matou village), site 3 (an e-waste dismantling area near Huangjitian village) and site 4 (an e-waste dismantling area near Jinsha village) are shown in Fig. 1. Samples 1-8 were collected from Site 1, samples 10-20 from Site 2, samples 21-28 from Site 3 and samples 30-36 from Site 4, respectively. The numbers of samples and plant species are given in Table S2, Supplementary material. Each soil or plant sample was a composite of four subsamples.

All the samples were wrapped with aluminum foil and put into polythene zip-bags. Plant roots and leaves were first rinsed carefully with tap water, and then washed thoroughly with deionized

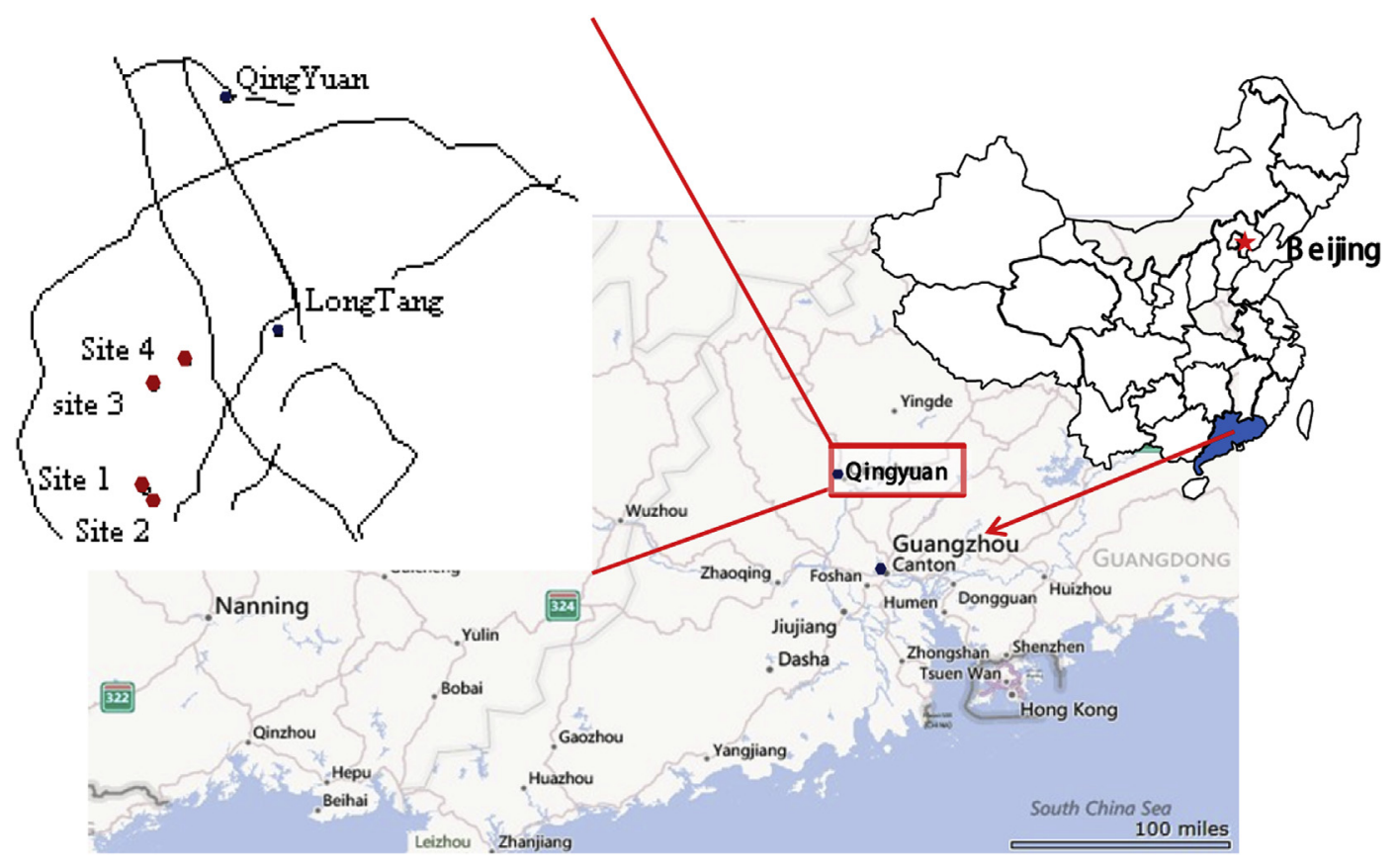

Fig. 1. Study area and the sampling sites. 
water, blotted with filter paper and weighed. The soil samples were ground and sieved $(<0.25 \mathrm{~mm})$. All the samples were then frozen at $-50{ }^{\circ} \mathrm{C}$ overnight, freeze-dried for $48 \mathrm{~h}$ in a lyophilizer (FD-1, Beijing Boyikang Instrument Ltd, Beijing, China), and weighed to determine their dry weights. The dried samples were chopped finely and stored in glass containers at $-20{ }^{\circ} \mathrm{C}$ before chemical analysis.

\subsection{Extraction and analysis}

Extraction and cleanup of PBDEs and MeO-PBDEs were based on the methods reported by López et al. (2009) and Wang et al. (2011a), and detailed descriptions of sample extraction and analysis methods are provided in the Supplementary material. ${ }^{13} \mathrm{C}-\mathrm{PCB}-$ 141, PCB-30 and PCB-209 were added as surrogate standards to the samples prior to extraction and ${ }^{13} \mathrm{C}-\mathrm{PCB}-208$ was added to the final solutions as an internal standard. An Agilent 7890 GC-MS (5975 inert) (Agilent, Palo Alto, CA, USA), HP-5MS column $(30 \mathrm{~m} \times 0.32 \mathrm{~mm}$ i.d., $0.25 \mu \mathrm{m}$ film thickness) and DB-5HT column (15 $\mathrm{m} \times 0.25 \mathrm{~mm}$ i.d., $0.1 \mu \mathrm{m}$ film thickness) (J \& W Scientific, Folsom, CA) were used for the analyses of PBDEs and MeO-PBDEs.

The extraction and cleanup procedures for OH-PBDEs in plants have been reported in our previous study (Wang et al., 2011b), and the details are provided in the Supplementary material. OH-PBDE analysis was performed with a UPLC-MS/MS consisted of a Waters Acquity UPLC Sample Manager and a Waters Acquity UPLC Binary Solvent Manger connected to a Waters Xevo TQ MS triple quadrupole mass spectrometer equipped with an ESI source (Waters, Milford, MA, USA). A reversed-phase chromatography was performed by Waters ACQUITY UPLC BEH $\mathrm{C}_{18}$ column (2.1 $\mathrm{mm} \times 100 \mathrm{~mm}$ i.d., $1.7 \mu \mathrm{m}$ particle size, Waters, Milford, MA, USA). The details of UPLC-MS/MS method are provided in the Supplementary material.

\subsection{Quality Assurance and Quality Control (QA/QC)}

Proper handling was employed from sample collection to chemical analysis to minimize the potential sample contamination, cross contamination, and PBDE degradation. All equipments were rinsed with acetone and hexane to avoid contamination. The method QC was ensured through analysis of solvent blanks and standards, procedural blanks, surrogate standards and spiked blanks. A procedural blank and a spiked blank were incorporated for every batch of 6 samples. No target analytes were detected in blanks. The limit of detection (LOD) for PBDEs, MeO-PBDEs and OHPBDEs was estimated based on a signal-to-noise ratio $(\mathrm{S} / \mathrm{N})$ of 3 . The LODs were in the range of $8-1920,32-60$ and $30-216 \mathrm{pg} \mathrm{g}^{-1}$ in soils and plant tissues for all the PBDE, MeO-PBDE and OH-PBDE congeners $(n=6)$. Recoveries of the surrogate standards of PCB-30, ${ }^{13}$ C-PCB-141, PCB-209, ${ }^{13}$ C-6-OH-BDE47 were $70.3-86.9 \%$, 70.6-95.8\%, 81.2-98.7\%, 72.3-90.2\%, respectively. Recoveries of PBDE, MeO-PBDE and OH-PBDE congeners ranged 71.6-112.4\%, $70.2-105.5 \%$ and $72.5-105.8 \%$ in the matrix spiked samples, respectively.

\subsection{Data analysis}

For samples with contaminant concentrations below LOD, zero was used for the calculations. Because no target analytes were detected in blanks, concentrations reported are not blank corrected. All of the results were expressed on a dry weight basis. Means and standard deviation were calculated from triplicates. Statistical analysis was performed using Microsoft Excel XP and Origin 7.5 (OriginLab Corporation). Statistical significance between datasets was tested by analysis of variance (ANOVA), and all significance tests were two sided, using $P<0.05$ as the level of significance.

\section{Results and discussion}

\subsection{The occurrence and distribution of PBDEs in the soils}

A total of 41 PBDE congeners (mono- through deca-BDEs) were identified in the soil samples (Table 1) with BDE-209 as the predominant congener. The $\sum$ PBDE concentrations ranged from 13.9 to $13,251.2 \mathrm{ng} \mathrm{g}^{-1}$ dry weight (dw) (mean, $898.3 \mathrm{ng} \mathrm{g}^{-1} \mathrm{dw}$ ), and the concentration ranges and distribution profiles of PBDE homologues are shown in Figs. 2(A) and S1(A), respectively. The $\sum$ PBDE levels were significantly higher $(P<0.05)$ in the e-waste dismantling areas (sites 2, 3 and 4) than those in the residential area of Matou village (site 1) near the e-waste dismantling area. BDE-209 concentrations in the soils ranged from $5.0 \mathrm{ng} \mathrm{g}^{-1}$ to 11,940.2 $\mathrm{ng} \mathrm{g}^{-1} \mathrm{dw}$ (mean, $783.5 \mathrm{ng} \mathrm{g}^{-1} \mathrm{dw}$ ), much higher than those reported for some other e-waste sites in China (Leung et al., 2007; Ma et al., 2009). BDE-209 contributed $61.4-93.7 \%$ of the $\sum$ PBDE contents in the soils of sites 1,2 and 4 , and $37.7-53.2 \%$ for site 3, indicating that the commercial deca-BDE mixture (BDE-209) was the dominant pollution source in this area. The predominance of BDE-209 in soils has also been found in various regions around the world (Eljarrat et al., 2008; Environmental Agency Japan, 1991; Hale et al., 2003; Leung et al., 2007; Ma et al., 2009).

PBDE products include three major commercial mixtures: Penta-, Octa- and Deca-BDEs. A total of 14 congeners (BDE-49, 47, $99,100,154,153,183,196,197,203,207,208,206$ and 209) included in these commercial mixtures were detected in the soils, which contributed more than $80 \%$ (81.6-99.8\%, with the exception of

Table 1

Congeners and the total concentrations of PBDEs detected in the soil, plant root and leaf samples.

\begin{tabular}{|c|c|c|c|}
\hline Homologues & Soils & Roots & Leaves \\
\hline Mono-BDEs & BDEs-1,2,3 (0.04-3.2, mean, 1.3$)$ & BDEs-1,2,3 (n.d.-18.2, mean, 3.2) & BDEs-1,2,3 (0.4-17.5, mean, 8.2) \\
\hline Di-BDEs & BDEs-10,7,8,12/13,15 (0.6-13.0, mean, 2.0) & BDEs-10,7,8,12/13,15 (0.7-22.5, mean, 5.6) & BDEs-10,7,8,12/13,15 (1.2-23.3, mean, 9.2) \\
\hline Tri-BDEs & BDEs-32,17,25,33/28,35,37 (0.1-18.1, mean, 2.4) & BDEs-17,25,33/28,37 (n.d.-2.0, mean, 0.4) & BDEs-32,17,25,33/28,35,37 (n.d.-7.8, mean, 0.8) \\
\hline Tetra-BDEs & BDEs-49,71,47,66,77 (0.7-127.9, mean, 18.1$)$ & BDEs-49,47,66 (n.d.-20.4, mean, 3.5) & BDEs-49,71,47,66,77 (0.4-7.3, mean, 3.6) \\
\hline Penta-BDEs & BDEs-100,119,99,85,126 (n.d. ${ }^{a}-92.9$, mean, 13.2 ) & BDEs-100,99,85,77 (n.d.-13.5, mean, 2.0) & BDEs-100,119,99,85 (n.d.-5.2, mean, 0.9) \\
\hline Hexa-BDEs & BDEs-154, 153 (n.d. -42.8 , mean, 8.8) & BDEs-154,153 (n.d.-6.8, mean, 0.4) & BDEs-154 (n.d.-6.7, mean,0.7) \\
\hline Octa-BDEs & $\begin{array}{l}\text { BDEs-202,201,204/197,198/199/200/ } \\
\text { 203,196,205,194,195 (n.d.-219.6, mean, 15.0) }\end{array}$ & $\begin{array}{l}\text { BDEs-202,201,204/197, 198/199/200/203,196 } \\
\text { (n.d.-13.4, mean, 0.8) }\end{array}$ & \\
\hline Hepta-BDEs & BDE-183 (n.d. -751.5 , mean, 49.6 ) & BDE-183 (n.d.-60.2, mean, 4.2) & \\
\hline Nona-BDEs & BDEs-208,207,206 (n.d.-54.7, mean, 4.4) & BDEs-208,207,206 (n.d.-3.5, mean, 0.2) & \\
\hline Deca-BDEs & BDE-209 (5.0-11940.2, mean,783.5) & BDE-209 (n.d.-5.3, mean, 2.0) & \\
\hline
\end{tabular}

Data within parenthesis are the total concentrations (ng $\mathrm{g}^{-1} \mathrm{dw}$ ) of PBDE homologues in soils, plant roots and leaves, respectively.

a .d. $=$ not detected. 

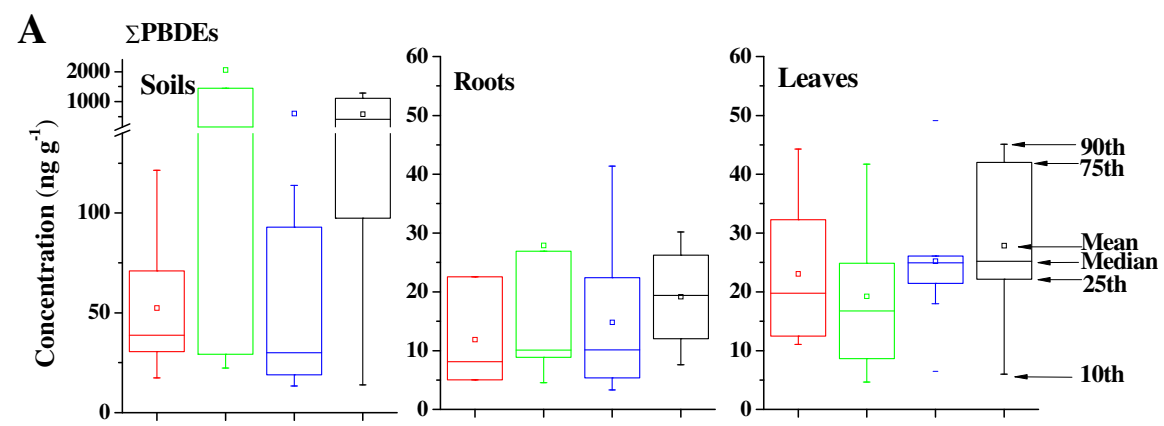

B

Red, Site 1; Green, Site 2; Blue, Site 3; Black, Site 4

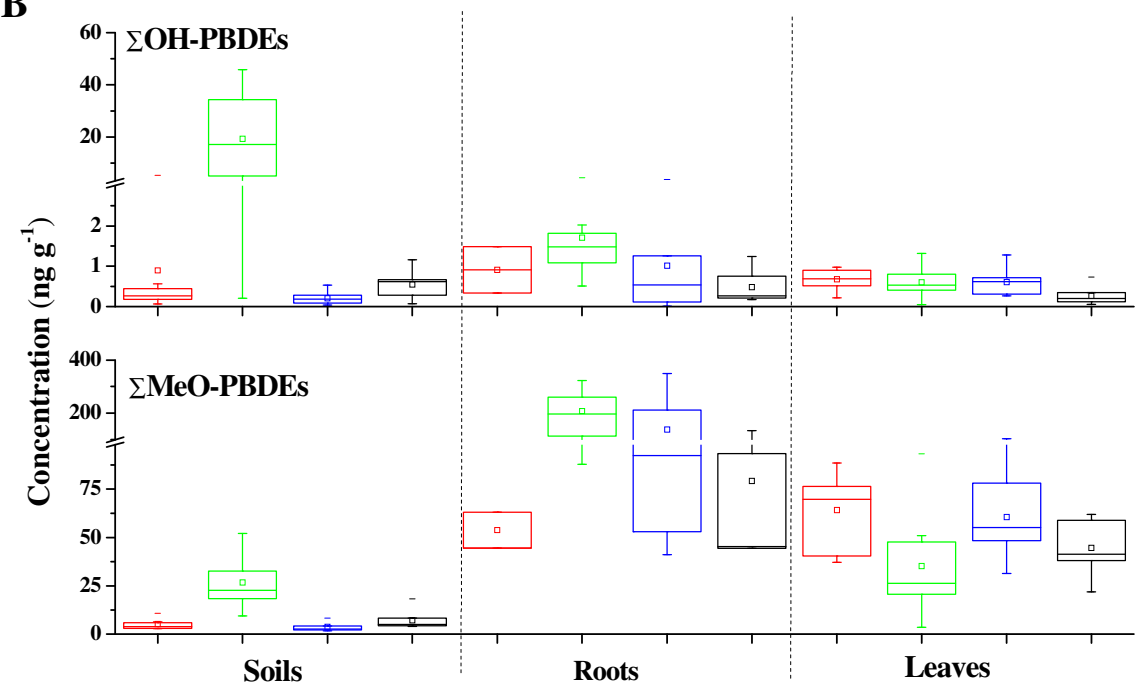

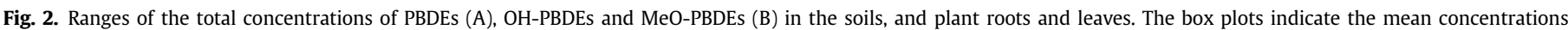
(square) and the 10th, 25th, 50th, 75th, and 90th percentiles. The markers have the same meanings in the figures below.

$66.3 \%$ in one soil sample) of the $\sum$ PBDEs in the soils. Nevertheless, except the congeners in these commercial PBDE mixtures, a sum of another 27 PBDE congeners were detected, which might be the debromination products of the commercial PBDEs. Previous studies also demonstrated that higher brominated PBDEs (including BDE209) in soils degraded into lower brominated PBDEs including some of the prohibited PBDEs (Betts, 2008; Huang et al., 2010; Wang et al., 2011a). Therefore, we should pay attention to not only the commercial PBDEs but also their debromination products when evaluating the adverse influences of PBDEs on the environment and human health. Significant positive correlations were found between BDE-209 concentrations and the concentrations of tetra-, penta-, hexa-, hepta-, octa- and nona-BDEs in the soils $(R=0.47,0.73,0.81,0.85,0.89,0.99, P<0.001)$, respectively. However, no significant correlations existed between BDE-209 concentrations and the concentrations of mono-, di- and tri-BDEs in the soils $(P>0.05)$. Such difference possibly contributed to the evidence that tetra- to deca-BDEs were mostly from the commercial PBDE mixtures, whereas mono-, di- and tri-BDEs were the debrominated products of different PBDE congeners in the commercial mixtures.

\subsection{The accumulation and distribution of PBDEs in the plants}

Thirty-three and twenty-six PBDE congeners were identified in plant roots and leaves, respectively (Table 1 ). Their concentration ranges and congener distributions are given in Figs. 2 and S1(B, C), respectively. The concentrations of $\sum$ PBDEs in plant roots and leaves were in the range of 3.3-94.3 and 4.7-45.1 $\mathrm{ng} \mathrm{g}^{-1} \mathrm{dw}$ with mean values of 20.3 and $23.5 \mathrm{ng} \mathrm{g}^{-1} \mathrm{dw}$, respectively, which was higher than the concentrations in plants $\left(0-300 \mathrm{pg} \mathrm{g}^{-1} \mathrm{dw}\right)$ collected from the areas surrounding a seafood processing factory in Longkou, China (Sun et al., 2013a), but much lower than the concentrations in plants (70-5900 $\mathrm{ng} \mathrm{g}^{-1} \mathrm{dw}$ ) collected near a BFR manufactory in Laizhou Bay (Jin et al., 2008). This suggests that contamination of PBDEs in the soils at e-waste sites resulted in their increased accumulation in plants but at much lower levels than those caused by contamination from BRF manufactory.

A significant positive linear relationship existed between the concentrations of $\sum$ PBDEs in plant roots and soils $(R=0.80$, $P<0.0001)$. However, the distribution of the PBDE homologues in plants was different from that in the soils. For example, BDE-209 was the predominant congener in the soils, whereas it was only detected at low levels in some of the woody plant roots (ranging from $0.3 \pm 0.03$ to $5.3 \pm 0.6 \mathrm{ng} \mathrm{g}^{-1} \mathrm{dw}$ ). In addition, much higher proportion of lower brominated PBDEs (mono- through pentaBDEs) was found in plant roots (22.0-100\%, mean, $90.2 \%$ ) and leaves (80.5-100\%, mean, $97.9 \%$ ) than in the soils (0.4-49.9\%, mean, $19.7 \%$ ). These differences may result from a combination of causes including contribution of foliar uptake of PBDEs to their plant accumulation, preferential root uptake and translocation of the lower brominated PBDEs, and metabolic debromination of higher brominated PBDEs to lower brominated congeners inside plants.

Root concentration factors (RCFs) of PBDEs, defined as the ratios of their concentrations in roots to concentrations in soils on a dry weight basis, were calculated and the values were in the range of 0.01-1.2 (mean, 0.3). The RCF value was higher for the congeners which have lower $\log K_{\text {ow }}$ values (Fig. 3), and there is a negative 


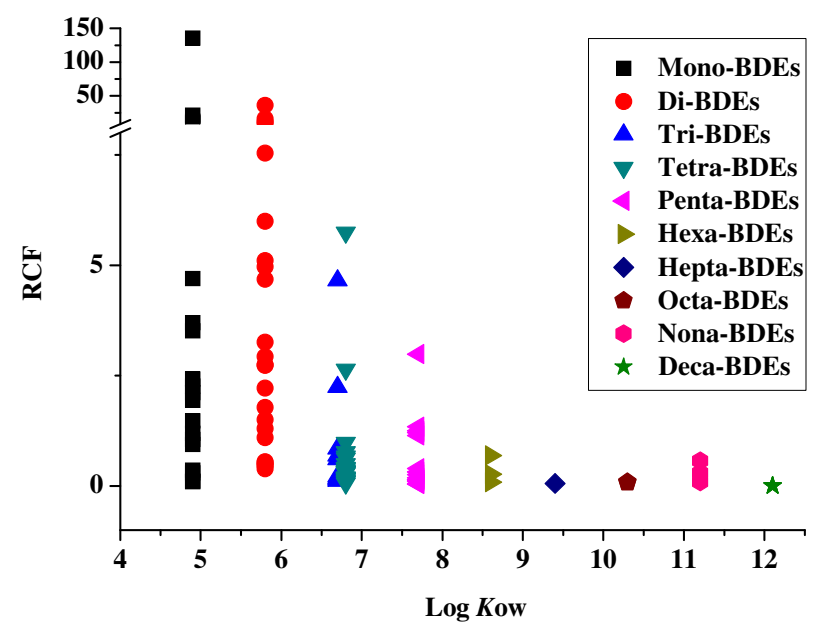

Fig. 3. Relationship between RCF and $\log K_{\mathrm{ow}}$ values for PBDE homologues in plants.

correlation between the values of RCFs and $\log K_{\mathrm{ow}}$ of PBDEs $(P<0.05)$, confirming that lower brominated PBDEs were more readily available for plant uptake than the higher brominated PBDEs. The RCF values for different plant species were in a wide range particularly for the congeners with low $\log K_{\text {ow }}$ (Fig. 3 ), and there is even no similarity between the RCF values for plants of the same species from different sampling sites, suggesting the differential uptake of PBDEs among plant species. There was no relationship between PBDE concentrations in the soils and plant leaves $(P>0.1)$. Moreover, we can see from Fig. S1(C) that distribution of PBDE congeners in plant leaves was very similar to each other for different plant species and even between different sampling sites. These facts suggest the main contribution of foliar uptake of PBDEs from the air to their accumulation in leaves.

\subsection{The composition and distribution of $\mathrm{OH}-\mathrm{PBDEs}$ and $\mathrm{MeO}-\mathrm{PBDES}$ in the soils and plants}

Concentration ranges and distribution profiles of OH-PBDEs and MeO-PBDEs in the soils and plant roots and leaves are shown in Figs. 2, 4 and 5 and S2, respectively. All of the twelve OH-PBDE congeners in the standards were detected in the soils and plant tissues. The range and mean concentrations of $\sum \mathrm{OH}-\mathrm{PBDEs}$ in the soils, plant roots and leaves were $0.04-45.8 \mathrm{ng} \mathrm{g}^{-1} \mathrm{dw}\left(6.0 \mathrm{ng} \mathrm{g}^{-1}\right.$ $\mathrm{dw}), 0.01-4.4 \mathrm{ng} \mathrm{g}^{-1} \mathrm{dw}\left(1.2 \mathrm{ng} \mathrm{g}^{-1} \mathrm{dw}\right)$ and $0.06-1.3 \mathrm{ng} \mathrm{g}^{-1} \mathrm{dw}$ (0.6 $\left.\mathrm{ng} \mathrm{g}^{-1} \mathrm{dw}\right)$, respectively, in the following order: $\sum \mathrm{OH}-$ PBDEs $_{\text {soils }}>\sum \mathrm{OH}-\mathrm{PBDEs}_{\text {roots }}>\sum \mathrm{OH}-\mathrm{PBDES}$ leaves (Fig. 2). All of the twelve $\mathrm{MeO}-\mathrm{PBDE}$ congeners in the standards were determined in the soil samples with 4'-MeO-BDE17 and 5-MeO-BDE47 detected in just a few samples (Fig. 6). Eleven and nine MeO-PBDEs were identified in roots (except for $4^{\prime}$-MeO-BDE17) and leaves (except for 4'-MeO-BDE17, 5-MeO-BDE47 and 4'-MeO-BDE49) (Fig. 6), respectively. The $\sum \mathrm{MeO}-\mathrm{PBDE}$ concentrations in the soils, roots and leaves were in the range of $1.7-52.2,41.1-349.6,3.5-$

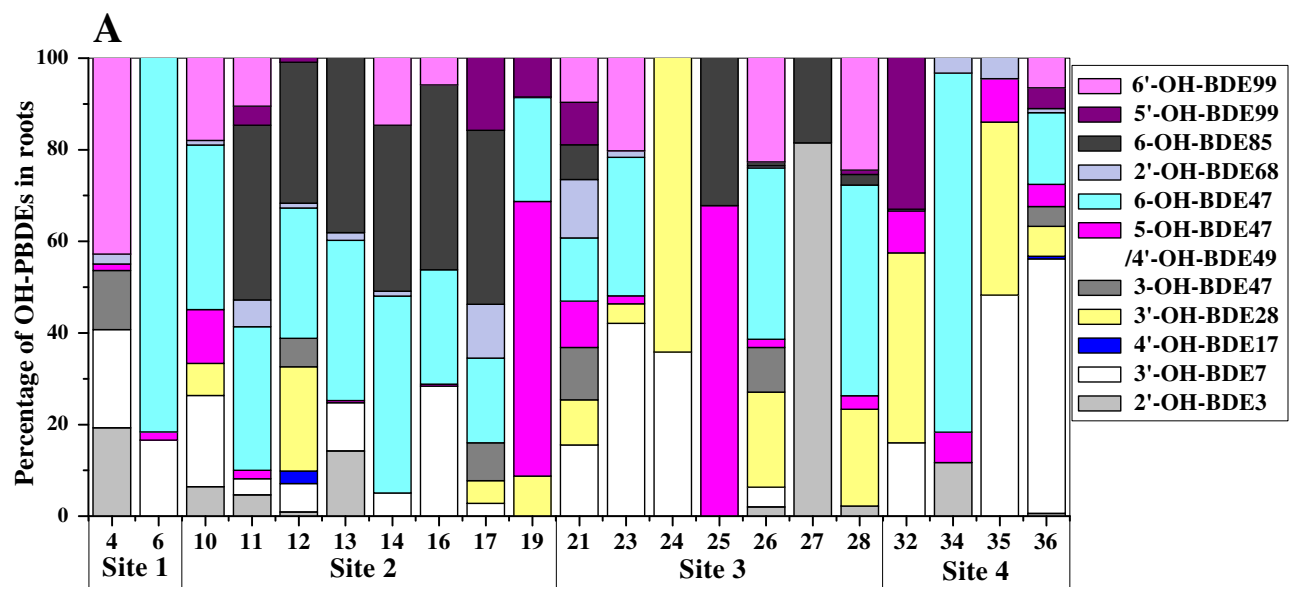

B

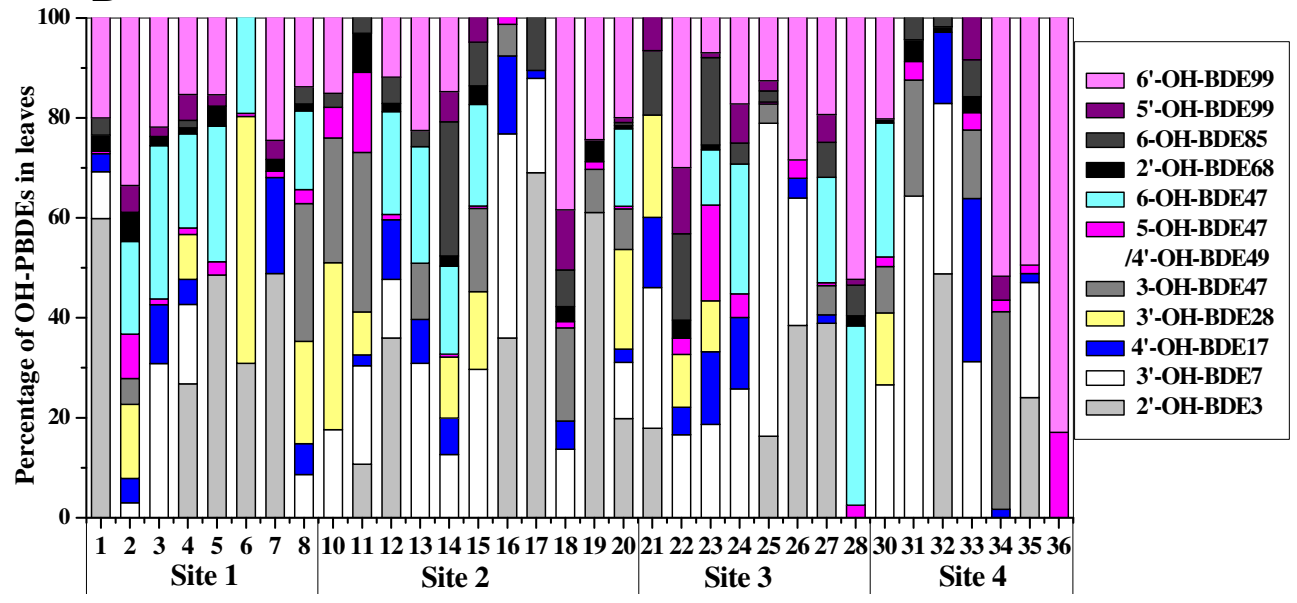

Fig. 4. Percentage distribution of OH-PBDEs in plant roots (A) and leaves (B). 
A

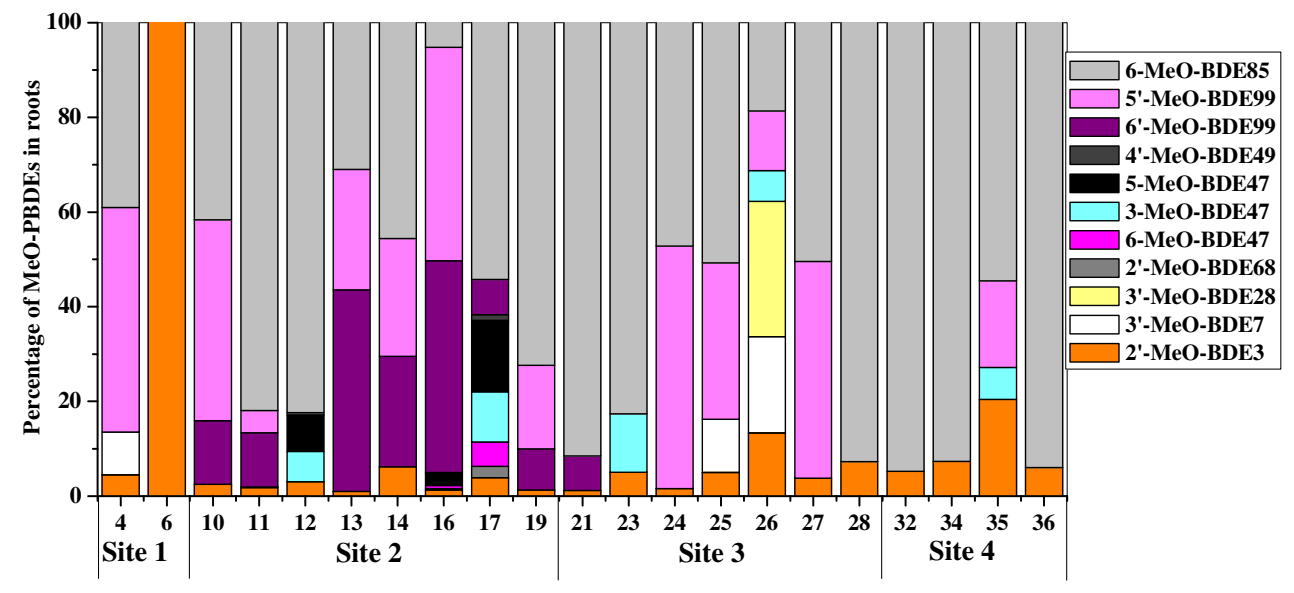

B

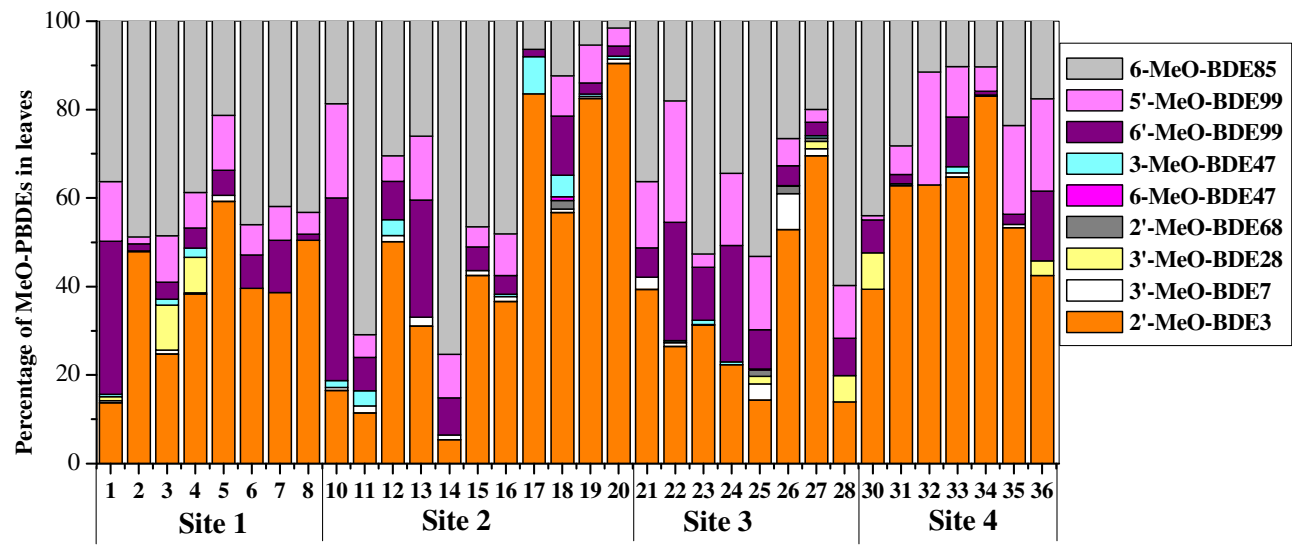

Fig. 5. Percentage distribution of MeO-PBDEs in plant roots (A) and leaves (B).

103.3 $\mathrm{ng} \mathrm{g}^{-1} \mathrm{dw}$ with mean values of $11.9,145.0$ and $51.5 \mathrm{ng} \mathrm{g}^{-1} \mathrm{dw}$, respectively, following the order of $\sum \mathrm{MeO}-\mathrm{PBDEs}_{\text {roots }}>\sum \mathrm{MeO}-$

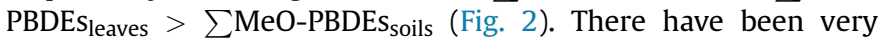
limited reports on the levels of OH-PBDEs and MeO-PBDEs in soils and plants. In comparison, the concentrations of OH-PBDEs and $\mathrm{MeO}-\mathrm{PBDEs}$ found in the soils from this e-waste recycling area were much higher than the levels reported for the soils around seafood processing factory in Longkou, China (Sun et al., 2013a) and sediments from Liaodong Bay, China and Muskegon Lake, Michigan, USA (Zhang et al., 2012; Bradley et al., 2011). Accumulations of $\mathrm{OH}-$ PBDEs and MeO-PBDEs in plants were also much higher than those found in plants collected in areas around a seafood processing factory which may provide the exposure source of MeO-PBDEs for plants (Sun et al., 2013a). These suggest that there possibly exists biotransformation of PBDEs to OH-PBDEs or MeO-PBDEs in the soil-plant system.

Fig. 2 clearly shows that the concentrations of $\sum$ MeO-PBDEs were much higher than those of $\sum \mathrm{OH}-\mathrm{PBDEs}$. Mean concentration ratios of $\sum \mathrm{MeO}-\mathrm{PBDEs}$ to $\sum \mathrm{OH}$-PBDEs were 25, 181 and 243 for the soils, plant roots and leaves, respectively. Higher concentrations of $\sum \mathrm{MeO}-\mathrm{PBDEs}$ than $\sum \mathrm{OH}-\mathrm{PBDEs}$ particularly in plants are likely related to higher accumulation of MeO-PBDEs due to their higher $\log K_{\text {ow }}$ values than those of the corresponding OH-PBDEs and short elimination half-life of OH-PBDEs (Kelly et al., 2008; Lai et al., 2011; Staskal et al., 2005). Significant positive linear relationships were found between the concentrations of $\sum \mathrm{OH}-\mathrm{PBDEs}$ and $\sum \mathrm{MeO}-$ PBDEs in the soils, plant roots and leaves (Fig. $6, R=0.86,0.48,0.40$, respectively, $P<0.05)$. Furthermore, the concentrations of the individual OH-PBDEs were also significantly correlated to their corresponding MeO-PBDE congeners (4'-OH-BDE17 and $4^{\prime}-\mathrm{MeO}-$ BDE17, 3'-OH-BDE28 and 3'-MeO-BDE28, 3-OH-BDE47 and 3-MeOBDE47, 5-OH-BDE47 and 5-MeO-BDE47, 6-OH-BDE47 and 6-MeOBDE47, 2'-OH-BDE68 and 2'-MeO-BDE68, 6-OH-BDE85 and 6-MeOBDE85, respectively) in the soils $(P<0.05)$. Significant correlations were also obtained in our previous hydroponic experiment between 3-OH-BDE28 and 3-MeO-BDE28, OH-BDE47 and MeOBDE47 in maize $(P<0.05$, Wang et al., 2012). It was therefore speculated that $\mathrm{OH}-\mathrm{PBDEs}$ and $\mathrm{MeO}-\mathrm{PBDEs}$ may share to some extent a common source or similar bioaccumulation behavior in the soils and plants. Interconversion between OH-PBDEs and MeOPBDEs is another possible explanation and recent studies have evidenced the interconversion between 6-OH-BDE47 and 6-MeOBDE47 in marine sediment (Zhang et al., 2012) and animal organisms by in vivo and in vitro exposures (Wan et al., 2009, 2010).

The ortho-substituted OH-PBDEs and MeO-PBDEs have been found the dominant compounds in environmental matrices and biotic samples and confirmed as natural occurring compounds (Lacorte and Ikonomou, 2009; Malmvärn et al., 2008; Teuten et al., 2005; Wan et al., 2009), whereas meta- and para-substituted $\mathrm{OH}$ PBDEs and MeO-PBDEs have been reported to be biotransformation metabolites during PBDE exposure (Malmberg et al., 2005; Marsh et al., 2006; Qiu et al., 2007; Wan et al., 2010). However, ortho-substituted OH-PBDEs and MeO-PBDEs have also been detected in PBDE exposure plants and animals (Qiu et al., 2007; 

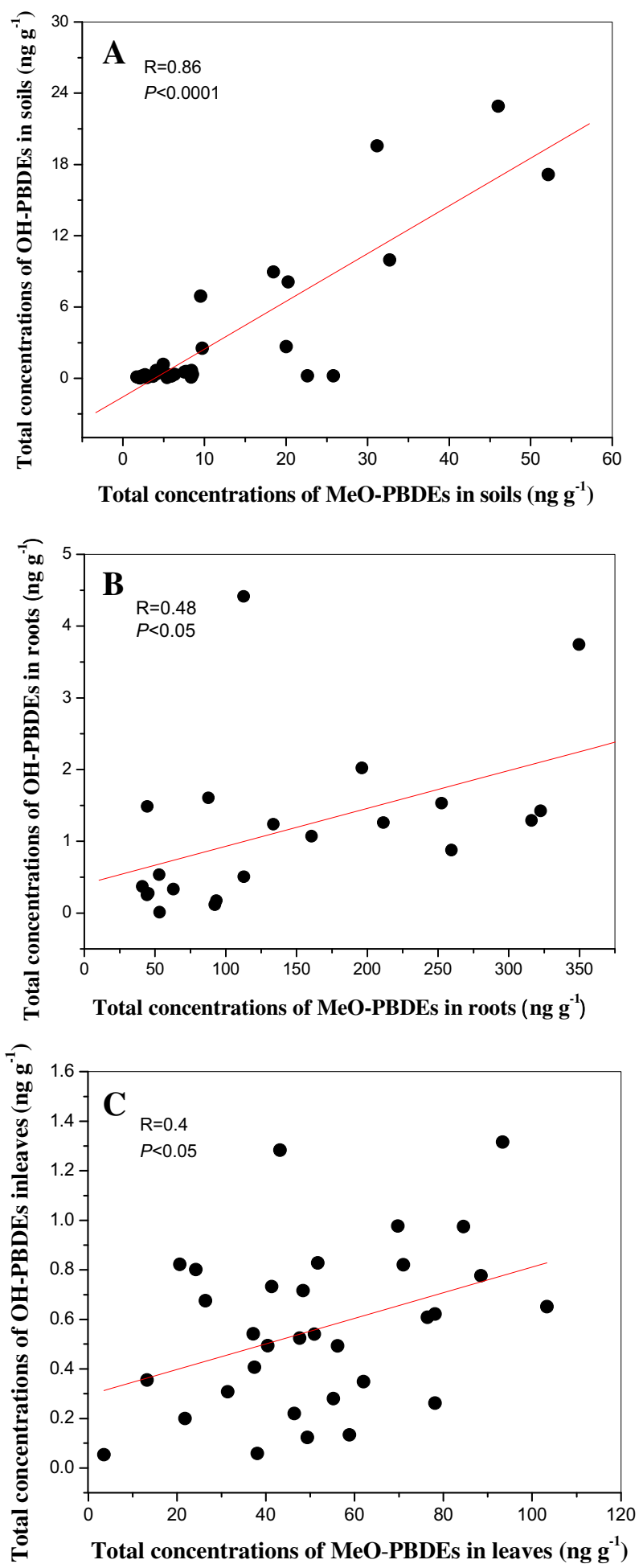

Fig. 6. Relationship between concentrations of OH-PBDEs and MeO-PBDEs in the soils (A), plant roots (B) and leaves (C), respectively.

Wang et al., 2012; Sun et al., 2013b), and meta- and parasubstituted compounds have also been found in environmental matrices (Marsh et al., 2004; Qiu et al., 2009; Sun et al., 2013a; Zhang et al., 2012). In the present study the ortho-, meta- and para-substituted OH-PBDEs and MeO-PBDEs were all detected in the soil and plant samples with 6-OH-BDE47, 6-OH-BDE85, 2'-OHBDE3, 6'-OH-BDE99, 3'-OH-BDE7, 6-MeO-BDE85 and 2'-MeO-BDE3 as the major congeners (Figs. 4 and 5 and S2). The proportional contributions of each kind of substituted congeners are provided in Table S3 in the Supplementary material. The proportions of orthosubstituted $\mathrm{OH}-\mathrm{PBDEs}$ (61.7\%, 56.8\% and 54.7\%) and MeO-PBDEs (55.5\%, 75.8\% and $86.7 \%$ ) were relatively higher than those of meta- plus para-substituted OH-PBDEs (38.3\%, 43.2\% and $45.3 \%$ ) and MeO-PBDEs (44.5\%, 24.2\%, 13.3\%) in the soils, plant roots and leaves, respectively, indicating the importance of the natural sources of OH-PBDEs and MeO-PBDEs for their accumulation in the soils and plants. Fig. 5 shows that the composition of MeO-PBDE congeners in leaves was very similar to each other for the plants from different sampling sites and even for plants of different species at the same sampling sites. There was also a similarity in composition of MeO-PBDEs in plant roots within sampling sites, but differences exist between sampling sites. However, the congener compositions of OH-PBDEs in plants, particularly in leaves, were highly variable among plant species and sampling sites (Fig. 4). This may suggest that naturally occurring sources of MeO-PBDEs contributed mainly to their accumulation in plants, while both natural sources and metabolic biotransformation contributed the occurrence of OH-PBDEs in plants. Furthermore, the meta- and para-substituted $\mathrm{OH}-\mathrm{PBDEs}$ and MeO-PBDEs were found as the dominant congeners with high concentrations and detection frequencies in some plant species such as Zea mays L. and Chrysanthemum indicum L. In comparison much larger proportions of metaplus para-substituted MeO-PBDEs in plants with higher detection frequencies were obtained in the present study compared with the results reported by Sun et al., and they did not found the meta- and para-substituted OH-PBDEs in the plant samples (Sun et al., 2013a). These may provide further evidences for the existence of biotransformation of PBDEs to OH-PBDEs and MeO-PBDEs or interconversion of OH-PBDEs and MeO-PBDEs in the soil-plant system in the e-waste recycling area. Nevertheless, we have to admit it is still hard to clearly identify the origin of OH-PBDEs and MeO-PBDEs in the naturally environment which deserves further investigation.

\section{Conclusions}

PBDEs, OH-PBDEs and MeO-PBDEs were analyzed in the soil and plant samples collected from an e-waste recycling area in Guangdong Province, Southern China in order to study their occurrence and distribution in the soil-plant system. A total of 41 PBDEs, 12 OH-PBDEs and $12 \mathrm{MeO}-\mathrm{PBDEs}$ were identified in the soil and plant samples. PBDEs in the soils are mainly composed of congeners which exist in the commercial mixtures with BDE-209 as the dominate congener. The $\sum$ PBDE levels were significantly higher in the e-waste dismantling areas than those in the residential area near the e-waste dismantling area. These demonstrate soil contamination of PBDEs is associated with their pollution sources from e-waste. Although there was a significant positive linear relationship between the concentrations of $\sum$ PBDEs in plant roots and soils, the distribution of the PBDE homologues in plants was different from that of soils with much higher proportion of lower brominated PBDEs in plants than in the soils, and foliar uptake from the air mainly contributed to the accumulation of PBDEs in leaves. It is interesting to note that the ortho-, meta- and para-substituted OH-PBDEs and MeO-PBDEs were all detected in the soil and plant samples. The proportions of ortho-substituted OH-PBDEs and MeOPBDEs were relatively higher than those of meta- plus parasubstituted OH-PBDEs and MeO-PBDEs in the soils, plant roots and leaves, indicative of the importance of their natural sources for plant accumulations. But the results obtained also suggest the existence of biotransformation of PBDEs to OH-PBDEs and MeOPBDEs or interconversion of OH-PBDEs and MeO-PBDEs in the soil-plant system at the e-waste recycling area. The results of the 
present study provide important information about characterization of PBDEs, OH-PBDEs and MeO-PBDEs in the soil-plant system. Transformation behaviors of PBDEs, OH-PBDEs and MeO-PBDEs in the soil-plant system need further investigation.

\section{Acknowledgments}

This work was funded by the National Basic Research Program of China (Project 2014CB441102), the National Natural Science Foundation of China (Project 21177139 and 41303073), Science Foundation of the Chinese Academy of Sciences (YSW2013B01) and Science Foundation of Northwest University (Project 13042).

\section{Appendix A. Supplementary data}

Supplementary data related to this article can be found at http:// dx.doi.org/10.1016/j.envpol.2013.09.021.

\section{References}

Betts, K., 2008. Does a key PBDE break down in the environment. Environ. Sci. Technol. 42, 6781.

Betts, K., 2009. E-waste reuse may be more pervasive than previously thought. Environ. Sci. Technol. 43, 6900-6901.

Bradley, P.W., Wan, Y. Jones, P.D., Wiseman, S., Chang, H., Lam, M.H.W., Long, D.T., Giesy, J.P., 2011. Polybrominated diphenyl ethers and methoxylated analogues in sediment cores from two inland lakes in Michigan. Environ. Toxicol. Chem. $30,1236-1242$.

Eljarrat, E., Marsh, G., Labandeira, A., Barceló, D., 2008. Effect of sewage sludges contaminated with polybrominated diphenylethers on agricultural soils. Chemosphere 71, 1079-1086.

Environmental Agency Japan, 1991. Chemicals in the Environment Report on Environmental Survey and Wildlife Monitoring of Chemicals in F.Y. 1988 and 1989. Environmental Agency Japan, Department of Environmental Health, Office of Health Studies, Tokyo, Japan.

Eriksson, J., Green, N., Marsh, G., Bergman, Å., 2004. Photochemical decomposition of 15 polybrominated diphenyl ether congeners in methanol/water. Environ. Sci. Technol. 38, 3119-3125.

Gerecke, A.C., Hartmann, P.C., Heeb, N.V., Kohler, H.P.E., Giger, W., Schimid, P., Zennegg, M., Kohler, M., 2005. Anaerobic degradation of decabromodiphenyl ether. Environ. Sci. Technol. 39, 1078-1083.

Hale, R.C., Alaee, M., Manchester-Neesvig, J.B., Stapleton, H.M., Ikonomou, M.G. 2003. Polybrominated diphenyl ether flame retardants in the North American environment. Environ. Int. 29, 771-779.

He, J.Z., Robrock, K.R., Alvarez-Cohen, L., 2006. Microbial reductive debromination of polybrominated diphenyl ethers. Environ. Sci. Technol. 40, 44294434.

Huang, H.L., Zhang, S.Z., Christie, P., 2011. Plant uptake and dissipation of PBDEs in the soils of electronic waste recycling sites. Environ. Pollut. 159, 238-243.

Huang, H.L., Zhang, S.Z., Christie, P., Wang, S., Xie, M., 2010. Behavior of decabromodiphenyl ether (BDE-209) in the soil-plant system: uptake, translocation and metabolism in plants and dissipation in soil. Environ. Sci. Technol. 44, 663-667.

Jin, J., Liu, W.Z., Wang, Y., Tang, X.Y., 2008. Levels and distribution of polybrominated diphenyl ethers in plant, shellfish and sediment samples from Laizhou Bay in China. Chemosphere 71, 1043-1050.

Kelly, B.C., Ikonomou, M.G., Blair, J.D., Gobas, F.A.P.C., 2008. Hydroxylated and methoxylated polybrominated diphenyl ethers in a Canadian Arctic marine food web. Environ. Sci. Technol. 42, 7069-7077.

La Guardia, M.J., Hale, R.C., Harvey, E., 2007. Evidence of debromination of decabromodiphenyl ether (BDE-209) in biota from a wastewater receiving stream. Environ. Sci. Technol. 41, 6663-6670.

Lacorte, S., Ikonomou, M.G., 2009. Occurrence and congener specific profiles of polybrominated diphenyl ethers and their hydroxylated and methoxylated derivatives in breast milk from Catalonia. Chemosphere 74, 412-420.

Lai, Y.Q., Chen, X.G., Lam Michael, H.W., Cai, Z.W., 2011. Analysis of hydroxylated polybrominated diphenyl ethers in rat plasma by using ultra performance liquid chromatography-tandem mass spectrometry. J. Chromatogr. B 879, 1086-1090.

Leung, A.O.W., Cai, Z.W., Wong, M.H., 2006. Environmental contamination from electronic-waste recycling at Guiyu, southeast China. J. Mater. Cycles Waste Manag. 8, 21-33.

Leung, A.O.W., Luksemburg, W.J., Wong, A.S., Wong, M.H., 2007. Spatial distribution of polybrominated diphenyl ethers and polychlorinated dibenzo- $p$ dioxins and dibenzofurans in soil and combusted residue at Guiyu, an electronic waste recycling site in Southeast China. Environ. Sci. Technol. 41, $2730-2737$.
Liang, X.W., Zhu, S.Z., Chen, P., Zhu, L.Y., 2010. Bioaccumulation and bioavailability of polybrominated diphynel ethers (PBDEs) in soil. Environ. Pollut. 158, 2387-2392.

López, P., Brandsma, S.A., Leonards, P.E.G., De Boer, J., 2009. Methods for the determination of phenolic brominated flame retardants, and by-products, formulation intermediates and decomposition products of brominated flame retardants in water. J. Chromatogr. A 1216, 334-345.

Luo, Y., Luo, X.J., Lin, Z., Chen, S.J., Liu, J., Mai, B.X., Yang, Z.Y., 2009. Polybrominated diphenyl ethers in road and farmland soils from an e-waste recycling region in Southern China: concentrations, source profiles, and potential dispersion and deposition. Sci. Total Environ. 407, 1105-1113.

Ma, J., Addink, R., Yun, S.H., Cheng, J.P., Wang, W.H., Kannan, K., 2009. Polybrominated dibenzo-p-dioxins/dibenzofurans and polybrominated diphenyl ethers in soil, vegetation, workshop-floor dust, and electronic shredder residue from an electronic waste recycling facility and in soils from a chemical industrial complex in eastern China. Environ. Sci. Technol. 43, 7350-7356.

Malmberg, T., Athanasiadou, M., Marsh, G., Brandt, I., Bergman, Å., 2005. Identification of hydroxylated polybrominated diphenyl ether metabolites in blood plasma from polybrominated diphenyl ether exposed rats. Environ. Sci. Technol. 39, 5342-5348.

Malmvärn, A., Marsh, G., Kautsky, L., Athanasiadou, M., Bergman, Å., Asplund, L. 2005. Hydroxylated and methoxylated brominated diphenyl ethers in the red algae Ceramium tenuicorne and blue mussels from the Baltic Sea. Environ. Sci. Technol. 39, 2990-2997.

Malmvärn, A., Zebühr, Y., Kautsky, L., Bergman, Å., Asplund, L., 2008. Hydroxylated and methoxylated polybrominated diphenyl ethers and polybrominated dibenzo-p-dioxins in red alga and cyanobacteria living in the Baltic Sea. Chemosphere 72, 910-916.

Marsh, G., Athanasiadou, M., Athanassiadis, I., Sandholm, A., 2006. Identification of hydroxylated metabolites in 2,2',4,4'-tetrabromodiphenyl ether exposed rats. Chemosphere 63, 690-697.

Marsh, G., Athanasiadou, M., Bergman, Å., Asplund, L., 2004. Identification of hydroxylated and methoxylated polybrominated diphenyl ethers in Baltic Sea Salmon (Salmo salar) blood. Environ. Sci. Technol. 38, 10-18.

Qiu, X.H., Bigsby, R.M., Hites, R.A., 2009. Hydroxylated metabolites of polybrominated diphenyl ethers in human blood samples from the United States. Environ. Health Perspect. 117, 93-98.

Qiu, X.H., Mercado-Feliciano, M., Bigsby, R.M., Hites, R.A., 2007. Measurement of polybrominated diphenyl ethers and metabolites in mouse plasma after exposure to a commercial pentabromodiphenyl ether mixture. Environ. Health Perspect. 115, 1052-1058.

Robrock, K.R., Korytar, P., Alvarez-Cohen, L., 2008. Pathways for the anaerobic microbial debromination of polybrominated diphenyl ethers. Environ. Sci. Technol. 42, 2845-2852.

Shih, Y.H., Wang, C.K., 2009. Photolytic degradation of polybromodiphenyl ethers under UV-lamp and solar irradiations. J. Hazard. Mater. 165, 34-38.

Sinkkonen, S., Rantalainen, A.L. Paasivirta, J., Lahtiper, M. 2004. Polybrominated methoxy diphenyl ethers (MeO-PBDEs) in fish and guillemot of Baltic, Atlantic and Arctic environments. Chemosphere 56, 767-775.

Stapleton, H.M., Letcher, R.J., Baker, J.E., 2004. Debromination of polybrominated diphenyl ether congeners BDE99 and BDE183 in the intestinal tract of the common carp (Cyprinus carpio). Environ. Sci. Technol. 38, 1054-1061.

Staskal, D.F., Diliberto, J.J., DeVito, M.J., Bimbaum, L.S., 2005. Toxicokinetics of BDE 47 in female mice: effects of dose, route of exposure, and time. Toxicol. Sci. 83, 215-223.

Sun, J.T., Liu, J.Y., Liu, Y.W., Jiang, G.B., 2013a. Levels and distribution of methoxylated and hydroxylated polybrominated diphenyl ethers in plant and soil samples surrounding a seafood processing factory and a seafood market. Environ. Pollut. 176, 100-105.

Sun, J.T., Liu, J.Y., Yu, M., Wang, C., Sun, Y.Z., Zhang, A.Q., Wang, T., Lei, Z., Jiang, G.B. 2013b. In vivo metabolism of 2,2',4,4'-tretabromodiphenyl ether (BDE-47) in young whole pumpkin plant. Environ. Sci. Technol. 47, 3701-3707.

Teuten, E.L., Xu, L., Reddy, C.M., 2005. Two abundant bioaccumulated halogenated compounds are natural products. Science 307, 917-920.

Ueno, D., Darling, C., Alaee, M., Pacepavicius, G., Teixeira, C., Campbell, L., Letcher, R.J. Bergman, A., Marsh, G., Muir, D., 2008. Hydroxylated polybrominated dipheny ethers (OH-PBDEs) in the abiotic environment: surface water and precipitation from Ontario, Canada. Environ. Sci. Technol, 42, 1657-1664.

Van den Steen, E., Covaci, A., Jaspers, V.L.B., Dauwe, T., Voorspoels, S., Eens, M., Pinxten, R., 2007. Accumulation, tissue-specific distribution and biotransformation of decabromodiphenyl ether (BDE209) in European starlings (Sturnus vulgaris). Environ. Pollut. 148, 648-653.

Verreault, J., Gabrielsen, G.W., Chu, S., Muir, D.C., Andersen, M., Hamaed, A. Letcher, R.J., 2005. Flame retardants and methoxylated and hydroxylated polybrominated diphenyl ethers in two Norwegian Arctic top predators: glaucous gulls and polar bears. Environ. Sci. Technol. 39, 6021-6028.

Wan, Y., Liu, F.Y., Wiseman, S., Zhang, X.W., Chang, H., Hecker, M., Jones, P.D. Lam, M.H.W., Giesy, J.P., 2010. Interconversion of hydroxylated and methoxylated polybrominated diphenyl ethers in Japanese medaka. Environ. Sci. Technol. 44, 8729-8735.

Wan, Y., Wiseman, S., Chang, H., Zhang, X.W., Jones, P.D., Hecker, M., Kannan, K. Tanabe, S., Hu, J.Y. Lam, M.H.W., Giesy, J.P., 2009. Origin of hydroxylated brominated diphenyl ethers: natural compounds or man-made flame retardants? Environ. Sci. Technol. 43, 7536-7542. 
Wang, S., Wu, T., Huang, H.L., Ping, H., Lu, A.X., Zhang, S.Z., 2011b. Analysis of hydroxylated polybrominated diphenyl ethers in plant samples using ultra performance liquid chromatography-mass spectrometry. Science China Chem. 54, $1782-1788$.

Wang, S., Zhang, S.Z., Huang, H.L., Christie, P., 2011a. Behavior of decabromodiphenyl ether (BDE-209) in soil: effects of rhizosphere and mycorrhizal colonization of ryegrass roots. Environ. Pollut. 159, 749-753.

Wang, S., Zhang, S.Z., Huang, H.L., Lu, A.X., Ping, H., 2012. Debrominated, hydroxylated and methoxylated metabolism in maize (Zea mays L.) exposed to lesser polybrominated diphenyl ethers (PBDEs). Chemosphere 89, $1295-$ 1301.

Wong, M.H., Wu, S.C., Deng, W.J., Yu, X.Z., Luo, Q., Leung, A.O.W., Wong, C.S.C., Luksemburg, W.J., Wong, A.S., 2007. Export of toxic chemicals - a review of the case of uncontrolled electronic waste recycling. Environ. Pollut. 149, $131-140$.
Yang, Z.Z., Zhao, X.R., Zhao, Q., Qin, Z.F., Qin, X.F., Xu, X.B., Jin, Z.X., Xu, C.X., 2008 , Polybrominated diphenyl ethers in leaves and soil from typical electronic waste polluted area in South China. Bull. Environ. Contam. Toxicol. 80, 340-344.

Yu, Y.X., Huang, N.B., Zhang, X.Y., Li, J.L., Yu, Z.Q., Han, S.Y., Lu, M., Van de Wiele, T., Wu, M.H., Sheng, G.Y., Fu, J.M., 2011. Polybrominated diphenyl ethers in food and associated human daily intake assessment considering bioaccessibility measured by simulated gastrointestinal digestion. Chemosphere 83, 152-160.

Zhang, K. Wan, Y., Jones, P.D., Wiseman, S., Giesy, J.P., Hu, J.Y. 2012. Occurrences and fates of hydroxylated polybrominated diphenyl ethers in marine sediments in relation to trophodynamics. Environ. Sci. Technol. 46, 2148-2155.

Zhao, G.F., Zhou, H.D., Wang, D.H., Zha, J.M., Xu, Y.P., Rao, K.F., Ma, M., Huang, S.B., Wang, Z.J., 2009. PBBs, PBDEs, and PCBs in foods collected from e-waste disassembly sites and daily intake by local residents. Sci. Total Environ. 407, $2565-2575$. 